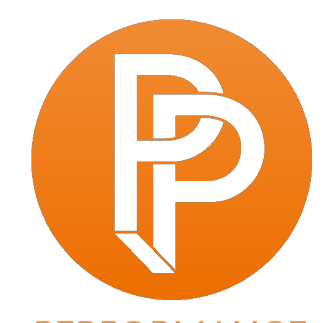

PERFORMANCE

PHILOSOPHY

\title{
RUNNING, RESISTANCE, AND RECOLLECTION: A CONVERSATION WITH OURSELVES THROUGH TIME
}

\author{
KATYE COE DANCER / COVENTRY UNIVERSITY \\ HETTY BLADES COVENTRY UNIVERSITY
}

\section{(to) constantly vent}

This fleeting, gentle, persistent action is concerned with interruption and the continuous movement of running. It addresses what is not seen and the way that imagination works when one witnesses the repeated presence, then absence, of a physical body, over time.

The work has been shown as a group piece and as a solo score and in the context of:

a four-day dance festival (original group commission at What_Now 2013);

a three-day open space conference (group at Dancer as Agent 2013);

a one-day symposium on process, (solo at Performing Process: Sharing Practice 2014);

a 12-week exhibition (solo as part of Volumes Project collective in MIRRORCITY October 2014 to January 2015).

As yet it has not been proposed to sit alongside or amidst a running-centered event.

A solo figure runs a continuous circuit, passing through the event or occupied space and extending into the neighbouring cityscape. The activity is traceable in her/the running body as she/they gather(s) sweat, endures tiredness and sheds excess thought.

In the event she/the figure is fleeting, marking time, bringing with her/ them as they/she passes through felt glimpses of the wider landscape. When the runner/she disappears they/she do/es 
not stop, but for those left in the gallery it continues as imagined, heard softly somewhere until she/they interrupt(s) once more.

The runners have a live phone line in their pocket as they run-this is fed back to a phone connected to speakers in the space where the running will happen intermittently-so the running is heard constantly and seen only fleetingly.

This piece of writing refers to the 12-week project of venting that was part of MIRRORCITY at the Hayward Gallery in London, where (to) constantly vent was invited as part of Volumes Project.

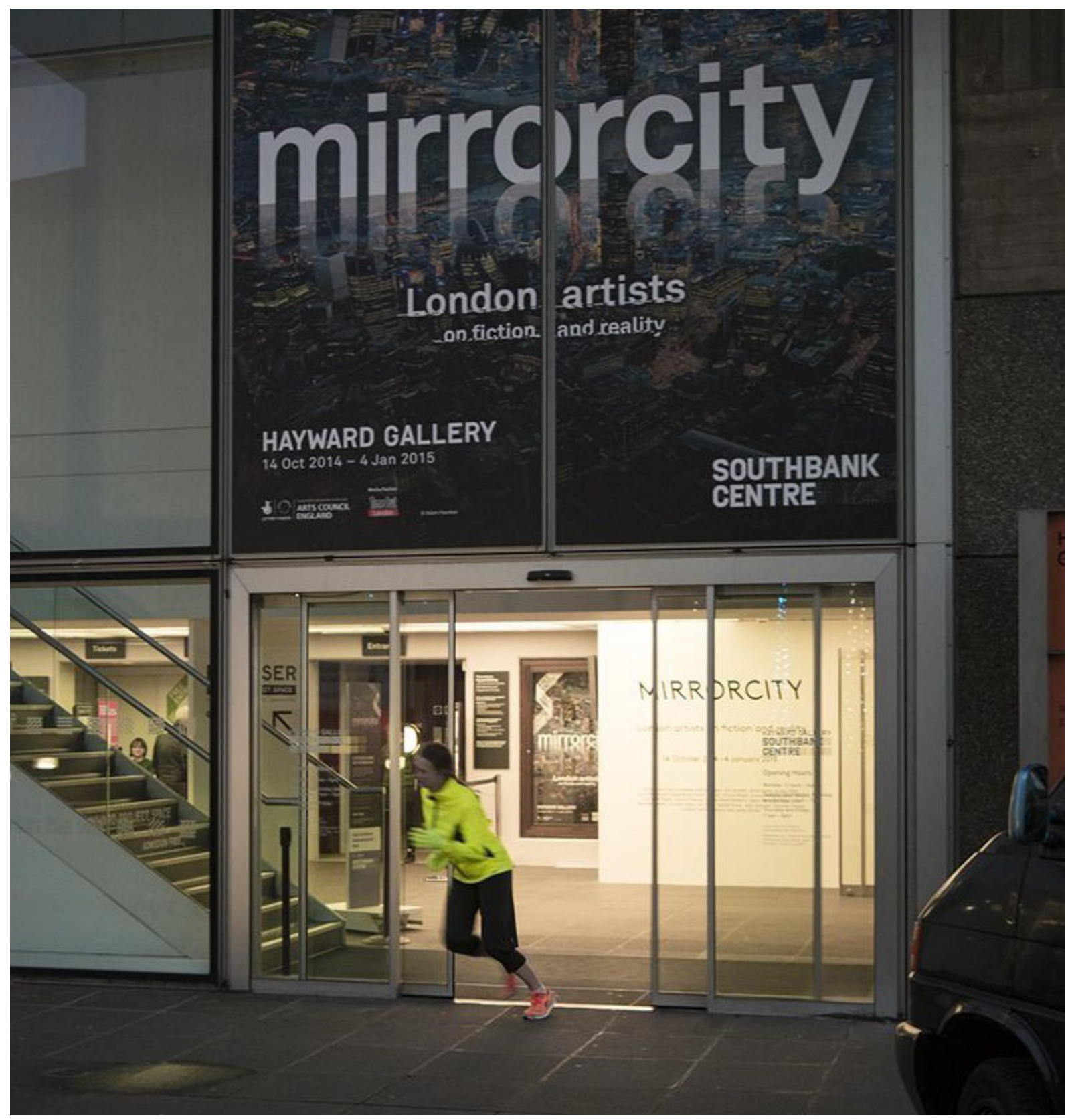

Installation view, MIRRORCITY: London artists on fiction and reality. Hayward Gallery, London, 13 October 2014-4 January 2015. Photo: (c) Michael Brzezinski. 
Volumes Project was a temporary collective of dance-artists who have gathered to show work as part of Hayward Gallery's exhibition MIRRORCITY. The project included six live works, typically shown one at a time, every day of the exhibition. These pieces moved amidst and between other artworks as they investigated the displacing effect of dance and choreography in an exhibition. Fleeting disruption was our job in relation to the collective. To occupy in the in-between spaces. I hope people who saw us recognised that they were also in the in-between spaces. Volumes Project included works by Neil Callaghan and Simone Kenyon, Katye Coe, Nicola Conibere, Charlie Morrissey, Florence Peake, and Rahel Vonmoos. It was conceived by Frank Bock, Nicola Conibere, and Martin Hargreaves. MIRRORCITY explored the effect the digital revolution has had on our experiences. Through artworks of a wide variety of media, its artists explored notions of fiction and reality.

\section{(to) distinguish between}

Between us we seem to have lots of questions about the practice and the work. In this piece we interrogate (to) constantly vent through our own memories, in order to think about the way it continues to exist through recollection, running and potentiality.

One year after the work took place at the Hayward Gallery we met to run and remember. The responses to our questions are taken from the conversation between us a year later, the performers' logbook, kept during the 12 weeks at the Hayward Gallery (2014-2015), and other people's writings about memory and running.

In some ways (to) constantly vent appears to belong to an emergent field of works in which running occurs in performative contexts. For example, Gregg Whelan's project The Long Run (2010-2015) investigated the relationship between running and contemporary performance practices. Public art organisation NVA's Speed of Light (2012) involved groups of runners travelling through public spaces to generate light installations. Emergency Room's Critical Run, an artist project that involves debating whilst running has taken place in a wide range of contexts across 20 countries. Andrew Filmer and his students at Aberystwyth University have made a series of running performances. Furthermore, Martin Creed's Work No. 850, performed at Tate Britain in 2008 involved performers sprinting through the gallery. So, how does (to) constantly vent relate to these other instances of running in performance? One witness describes the work as having "a radical disregard of convention"1, but why is this when it appears to belong to a performance convention? The answer it seems is in the intention and focus of the practice; I don't think venting is about running.

Isn't that the paradox of the work you're trying to express? On a wonderful chemical level, what happens when you run-the sense of achievement, oneness with the world, the extraordinary experience-alongside the ordinariness of running, the boredom of doing it? ${ }^{2}$ 
(to) recollect

When I remember an episode of my personal history I come into contact with events and experiences which are no longer present. My conception of my own life involves narratives in which such experiences are inter-related. We find it easy to engage in the peculiar sort of 'mental time travel' involved in such autobiographical memory, although we're often aware of significant limits to its reliability. ${ }^{3}$

\section{What is it that makes this work what it is?}

When we talk, I talk myself into it and then completely out of it again as well. It is what I am interested in practicing. Ways of approaching things that exist because of themselves, but also not in relation to anything except themselves.

Venting exists to be seen, but in fact it exists whether it's being seen or not. So there's a little bit of insistence of its being recognised because we're putting it into places where that activity is not usually or frequently seen. And hopefully because of the timing of the loops, it is revealed only just enough for it to be present. It was never my intention to insist through this work. If the running was constantly seen, it would have been insistent or demonstrative. Usually, vent's presence is marked by the constant sound of the running figure, but the sound didn't work properly in the Hayward Gallery, too much concrete.

The work has therefore taken on a different way of existing because it became more about it being seen and less about it being constantly heard. There's been a big shift. There was some recorded sound placed in the space instead, but mostly people didn't associate that sound with us running. I eventually realised that the live sound aspect of it was no longer possible. And so we became only present in the live body.

When we vent there's always a time, often quite precise timing, going on because we are running laps, and entering a building and because each runner is performing on shifts.

The whole purpose of venting at Hayward was to bring people's attention a little away from the art and into the space(s) between where the art was happening.

This idea of performing when you are not performing is quite tricky/ unusual/ naive.

In the work we keep running, all the time, in the 'performance space' of the gallery and into the outside cityscape.

Yes and that felt to me, like otherwise why do it? It's not like we're showing running. 


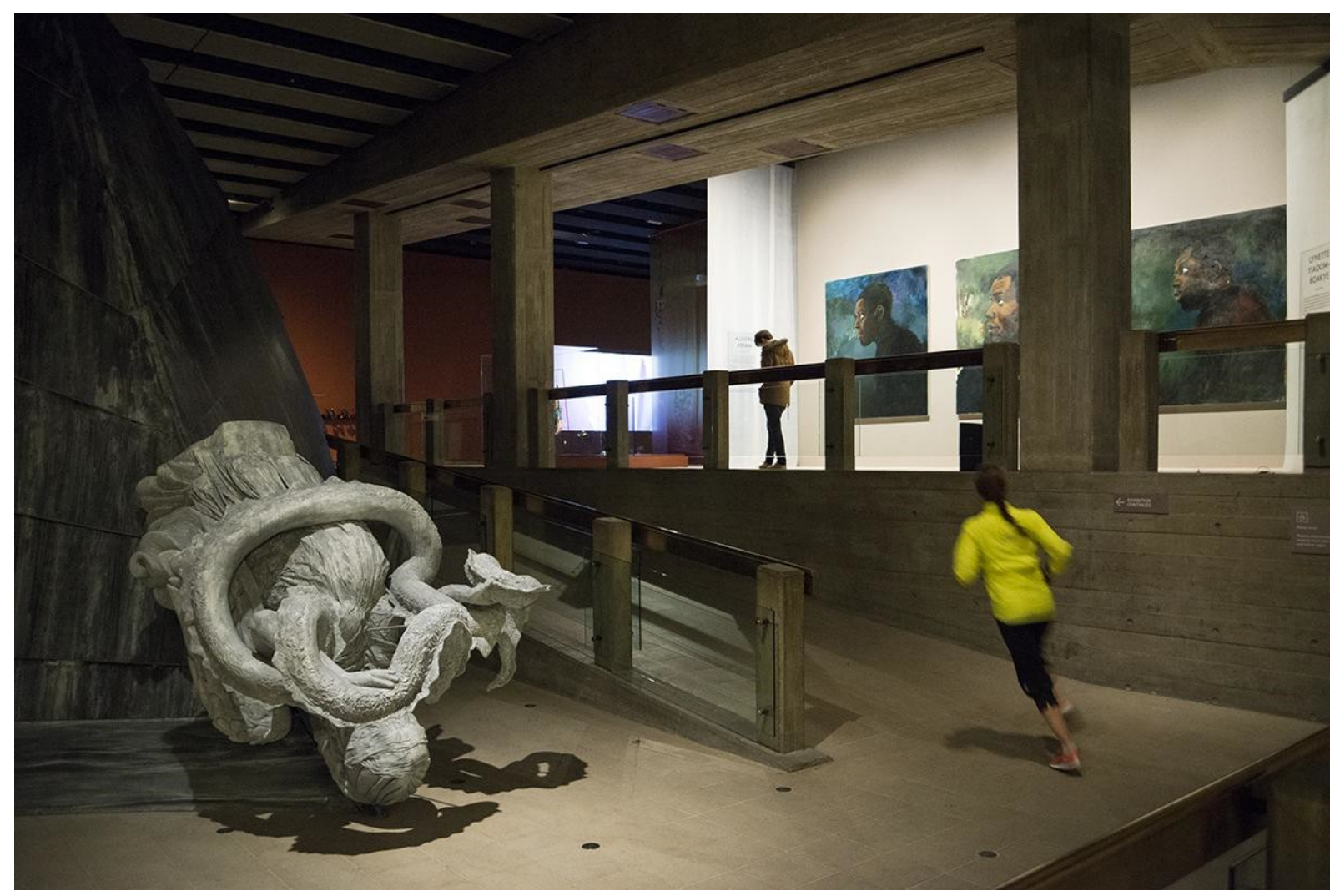

Installation view, MIRRORCITY: London artists on fiction and reality.

Hayward Gallery, London, 13 October 2014-4 January 2015. Photo: (c) Michael Brzezinski.

That is why I have become more exact about who can vent too. It has become clear that it is important to work alongside other people who run and also have an understanding of performance. It would be a completely different work with athletes for example. I rely on the performer runners understanding or at least being up for questioning the idea that we are not showing running.

And no it couldn't work if we were only running through the gallery, actually it seems very abstract to think about that because it's a completely different proposition. But we could do 12 weeks with no risk of injury of tiredness, because you could just be flying through the gallery for those times, but the work wouldn't be the work then.

And in a way that's one of the things that's interesting about the work, is that it doesn't really matter whether they think that. Or ... It's like about something more than ... It's at once intrinsically related to being seen and yet completely detached from what it is understood as.

How can the experience of the practice be articulated?

In order to have running in my practice world again, not even consciously, I have done to running what I have done in all my dance practices, which is to take the end out of it. Take the intention of completing something out. I left competitive or race-based running behind a long time ago. I 
stopped running with a watch or a distance monitor. Actually even when I was still training for my last marathon I didn't usually run with anything more than a rough idea of where I might go. I got pretty good at feeling speed and time and strangely in this venting practice I have got pretty bad at that again. I think vent might illustrate that, in that it doesn't have a start or an end. It's not linear in terms of its pathway. The time constraints are really related to how long the event/ person/ institution wants us to do it for. It's not related to a distance.

It's about consciousness, about being in a certain place, or acknowledging that a shift in consciousness that makes it practice rather than training.

[T]rying to answer a philosophical question using science won't work [....] you won't get close to the phenomenon of experiencing it. ${ }^{4}$

I was thinking about the honesty or integrity with which we practice venting. And it's a given. The purpose of the work is entirely reliant on the fact that the running is being practiced. And at the same time I don't imagine that that fact necessarily affects a person's viewing of it.

Sometimes I envisage this work similar to an experience of closing your eyes and then opening them again. When I close my eyes, material on the inside lights up while I can no longer see the exterior context in which something is happening. When I open my eyes again, the outside context comes back and the sensitised inside material view becomes quieter or slips into relief. (to) constantly vent does involve going into something and coming out again, many times. It

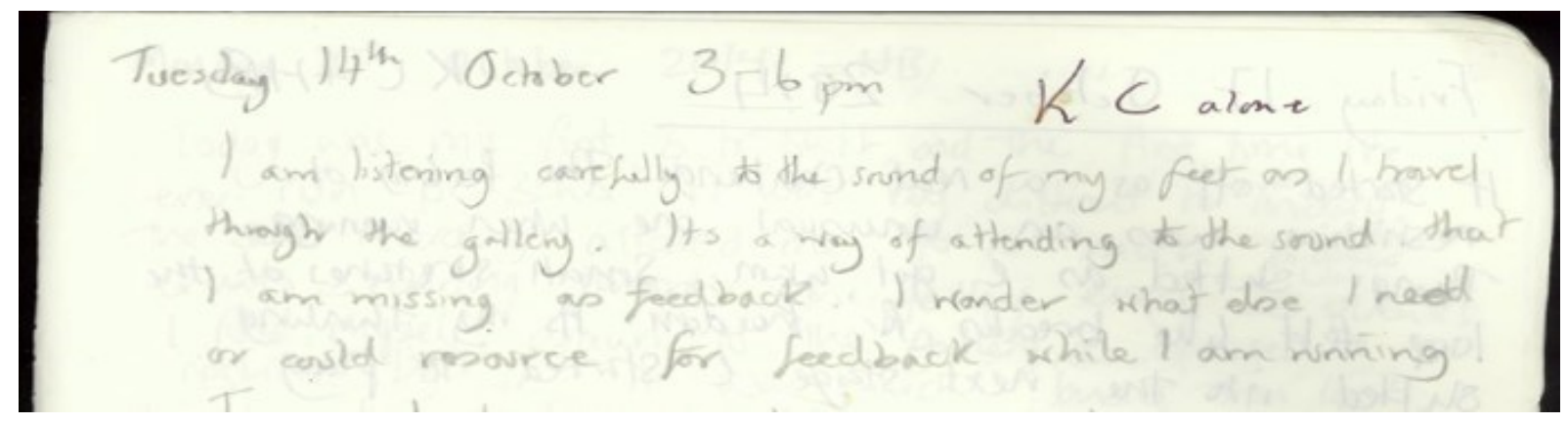

Performers' field notes from (to) constantly vent at MIRRORCITY: London artists on fiction and reality. Hayward Gallery, London, 13 October 2014-4 January 2015. Writing by Katye Coe, Taylan Halici, Hetty Blades, Hannah McBrien, Jamila Rodrigues.

doesn't feel like disappearing and reappearing. We have talked about it before as disappearing and reappearing, but maybe it's more useful to think about it, or to negotiate it, as inside and outside.

As you cross the threshold you are in a really specific way of being in relation to other people, and as soon as you leave the gallery space you're in a really different relationship to people around you, but nothing's changed. 
And in the activity, the running you literally come in and go out, and that has always been the case in venting, in all its iterations. Coming into the building you drop away from your usual relationship with the activity and the world, and when you come out of the building it is a little bit like opening your eyes because everything falls back into its usual set of conditions. So the conditions are unusual inside and usual outside.

[E]xplicit memories, roughly, can be accessed verbally or otherwise by the subject, whereas implicit memory is memory without awareness. ${ }^{5}$

I usually experienced a slight disappointment when I left the Hayward Gallery on each loop.

And yet there was a simultaneous feeling of relief too, because you can attend to things that there is room for only outside, things you can do in the usual 'outside' context of running that you can't do in the gallery. My focus is more general, lighter perhaps when I run outside. My thoughts are allowed to drift much more. I have a less precise path on the ground, I might change speed or direction more freely.

Hmmm ... so there are conditions that I set up when I am here (eyes closed) and in a more precise internal environment. It's much more exact, my sense of this body, than it generally is when it is out in the world. I don't know. Maybe it's not helpful. It seems closer than appearing and disappearing.

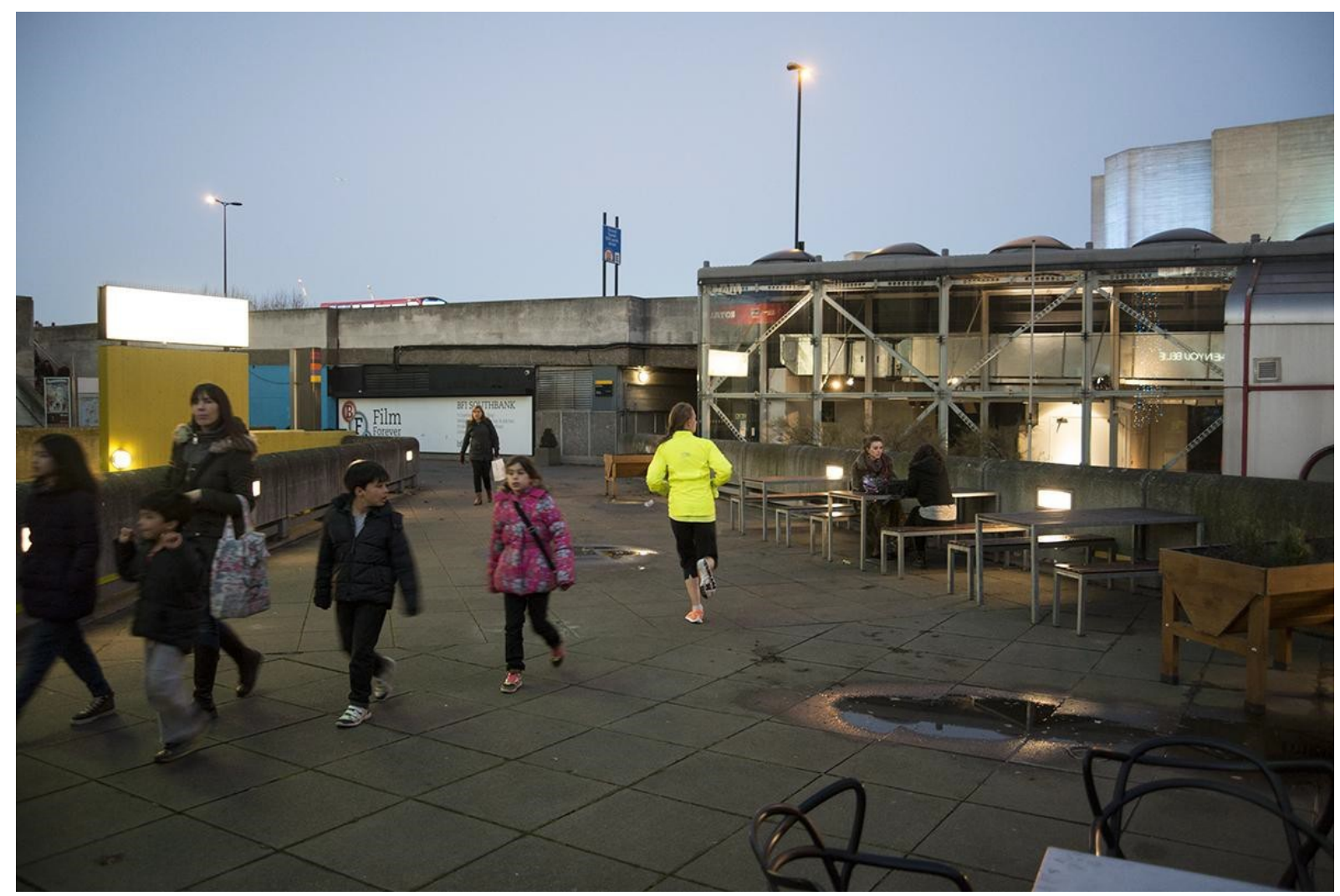

Installation view, MIRRORCITY: London artists on fiction and reality.

Hayward Gallery, London, 13 October 2014-4 January 2015. Photo: (c) Michael Brzezinski. 
I am here to get some purchase on how a performance maker might begin to work with a practice that is arguably the thing that makes us human: an action, a doing, that perform humanness. ${ }^{6}$

It would be unspectacular looking at the individual—watching one runner is not interesting. ${ }^{7}$

But I can feel my interest in what the solo runner undoes but I can't quite articulate it.

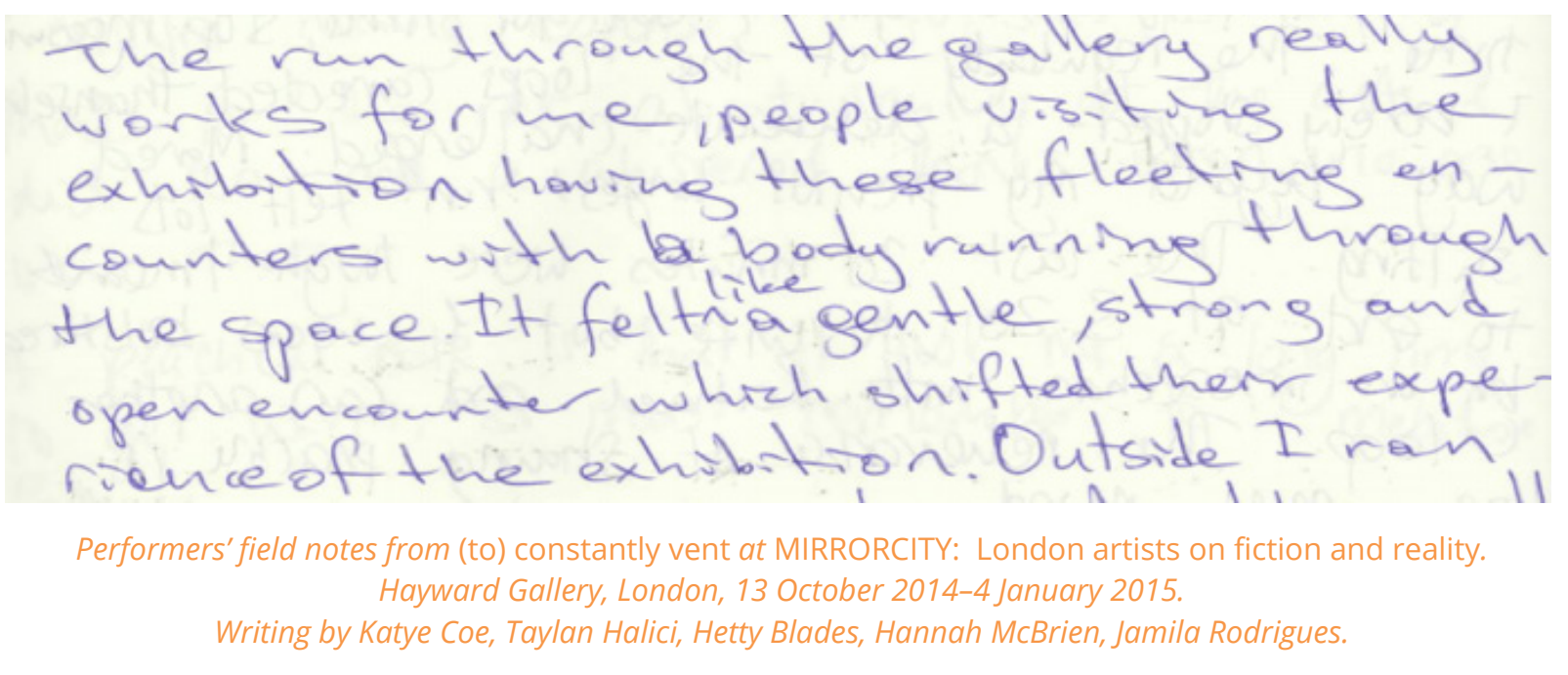

What is the relationship between the practice and the choreographic?

There's something that we've just started to excavate in this conversation. Something about the inside to outside to inside thing. And the continual action, that there's a thing that's happening anyway, so its presence keeps going into relief and then it returns to the foreground. It retreats and returns and there's something about that that I haven't recognised before. What does that tide of activity do to the frame of an event?

... and then there's something about this aspect of the practice where as performers we take it very seriously. We take its seriousness very seriously, we're very good performers in it. That is the essence of it, that it's happening and it's happening very seriously and honestly.

There's something there about this ongoingness, a resistance to a stable object, a thing that happens anyway that isn't cultivated specifically for consumption by an audience that is political anyway because it challenged conventional modes of producing performance and art. It puts labour in place of an artwork.

The great psychological minds would consider that to be the unconscious, the 'shadow'. The unconscious comes to the surface through physical activity filling a gap between the conscious and unconscious. ${ }^{8}$

We didn't stop. We didn't stop. 
In earlier versions of (to) constantly vent when we ran in a group, the group-ness meant that the exhaustion that you talked about experiencing solo and that I certainly experienced solo and also the loneliness, never occurred. We were never running on our own. But at the same time there was this sort of absurd responsibility to the constant continuation of the activity because of the necessity of the live sound. I think that then carried energetically and in the memory of the work and as practice into the Hayward iteration, even though we didn't have the live sound to motivate us.

Memory is one of the most important ways by which our histories animate our current actions and experiences. ${ }^{9}$

Remembering is often suffused with emotion, and is closely involved in both extended affective states such as love and grief, and socially significant practices such as promising and commemorating. ${ }^{10}$

There is little opportunity for joined-up thinking because the effort involved in keeping going is simply too great. ${ }^{11}$

I have all these thoughts when I am running that I think are really profound and then I write them down and realise they are not very interesting.

The question about memory representing the past.... I can think this through in relationship to learning about the loops that we ran over and over ... I feel the content of the past when I am in the practice of repetition. I sense the past through the texture (of the environment and of myself in it). Memory reveals feeling states that are present because of the past.

[R]eally as I run I don't think much of anything worth remembering. ${ }^{12}$

How can memory traces represent past events or experiences? How can they have content? ${ }^{13}$

\section{How does the viewer experience this work?}

It comes back to how the doing is somehow placing practice in front of people, which feels different to performance. Of course it's performed because it is in this context, but because of the mode of showing, it doesn't quite fit.

Jonathan Burrows once talked about the nature of practices like this in a really brilliant way. And I risk misunderstanding him here but ... He said that [my] practice could be experienced as a political act. ${ }^{14} \mathrm{He}$ acknowledged that this is part of a larger conversation that examines the politics of practice, articulated by Deborah Hay and Juan Dominguez, amongst others. And although I don't fully understand it as a political act, there is something in what it is you're getting at that makes for a set of conditions, that undo the status quo.

Any political resistance is in relation to the thing you're resisting. 
And I don't know enough about political acts to understand enough about what the undoing is necessarily, which is why I wanted Jonathan to say it for me. I am wondering if there is something, as useful definition or frame where performativity is given edges. I avoid the writing sometimes because I am worried if I find out too much about it I will never want to do anything again.

Maybe it's the wrong way of thinking about it, but then it's like; what is specific about it? What is it to put practice in front of people? It is something specific in itself.

Yeah and yet, we can't have this conversation without it being put in front of people.

It also doesn't have an end to the people seeing it and it seems as though there's something integral to it being venting, which is to do with it being seen.

So how does the body-based discipline of contemporary performance practice react when the body has been rediscovered and reimagined as one defined by running and endurance? ${ }^{15}$

[T] he best explanations of the form and content of specific personal memories may often refer not simply to the past episode itself, but to multiple causes which span internal and external factors. ${ }^{16}$

They never see us end. It's not about finishing. It's not about the finish. They assume that we are doing it.

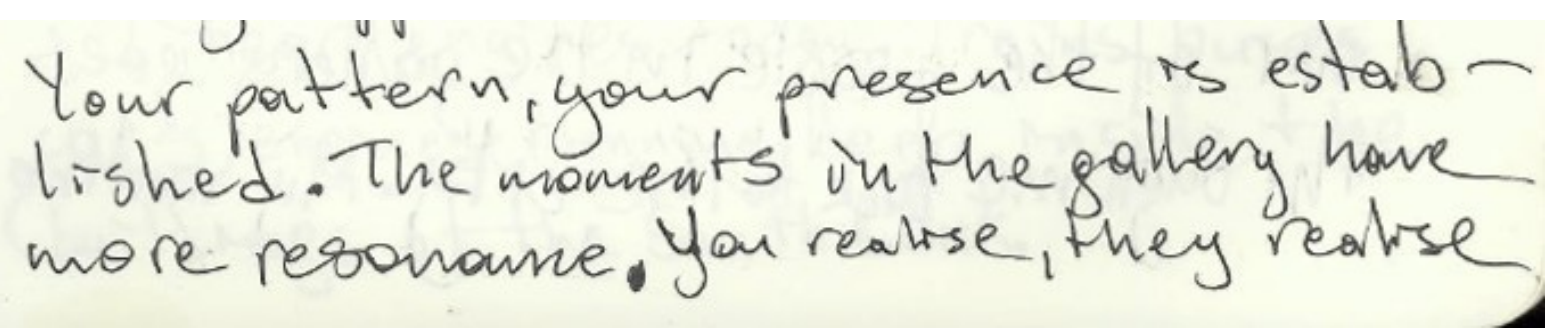

Performers' field notes from (to) constantly vent at MIRRORCITY: London artists on fiction and reality. Hayward Gallery, London, 13 October 2014-4 January 2015.

Writing by Katye Coe, Taylan Halici, Hetty Blades, Hannah McBrien, Jamila Rodrigues.

\section{I felt more resistance than empathy and compassion.}

If I see someone running I think about them running, I don't think about them starting or stopping. Shorter and staged versions are very different. The performer in that situation might be manipulated into a relationship with the audience, in the gallery you are not.

It's not such a seductive relationship. 


\section{Works cited}

14 Burrows, Jonathan. 2017. Personal Correspondence.

1 MacPherson, Hamish. 2013. Personal conversation. What_Now Festival: London.

12 Murakami, Haruki. 2008. What I Talk About When I Talk About Running. London: Harvill Secker. Cited in Whelan (2012)

2,4,7,8 NVA. 2011. 'Why We Run'. Accessed February 24, 2016

http://nvaspeedoflight.org.uk/images/518239434f5cf-investigations\%20pdfamfinal.pdf

3,5,9,10, Sutton, John. 2010. 'Memory'. Stanford Encyclopedia of Philosophy. Accessed February 24, 2016.

13, 16 http://plato.stanford.edu/entries/memory/

6,11,15 Whelan, Greg. 2012. 'Running Through a Field: Performance and Humanness'. Performance Research 17 (2): 110-120. https://doi.org/10.1080/13528165.2012.671079

\section{Biographies}

Katye Coe is a freelance dance artist based in the UK. She is a Senior Lecturer in Dance at Coventry University and the founder director of Decoda.

Hetty Blades is a Postdoctoral Research Assistant in the Centre for Dance Research (C-DaRE) at Coventry University.

(c) 2017 Katye Coe and Hetty Blades

(c) (7) (2) Except where otherwise noted, this work is licensed under a Creative Commons AttributioncC) NonCommercial-ShareAlike 4.0 International License. 